given, the previous rise of temperature not having reached normal urtil in A.M.

On March rath mj was injected. The temperature rose to ror. $6^{\circ} \mathrm{F}$. in twelve hours. On this oceasion the injection was made in the chest wall.

On March ${ }_{3}$ th an injection of $m$ j was again made in the chest wall. The (ess, temperature being highest at 2 P.M. (tor ${ }^{\circ} \mathrm{F}$ ). On the fol lowing day no injection was given.

On March $x_{5}$ th an injection of $\mathrm{mj}$ was given. The temperature rose during reaction to $100^{\circ}$

On March r6th mj was injected, and the temperature rose to $10.2^{\circ} \mathrm{F}$. The general condition was good, the ulcerative processes more active, and the mours certainly diminishing

On March r th, r8th, ryth, and $20 t h$, similar injections we: e made. The temperature was highest generally about ten hour's afterwar's, but did no reach above $r 0^{\circ} \mathrm{F}$. On March soth a large piece of the llough was removed from the tumour in the occiput, exposing part of the occipita bone to the left, which was rough and bare.

No injection was given on March $2 r s t$, but on $\mathrm{March}^{2}$ and $\mathrm{mj}$ was inected. The temperature rose to roo. $2^{\circ} \mathrm{F}$

March 23rd. Injection of $1_{2}^{\frac{1}{2}}$ minim, temperature $10.2^{\circ} \mathrm{F}$

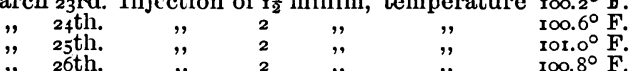

The tumour on left" side had almost disappeared : and on March 27 th an injection of 2 minims. was given; temperature ror ${ }^{\circ} \mathrm{F}$. On March 28 th $n$ injection was given, but there was a rise of temperature in the evening, which was thought to be due to some sepsis of ulcers as distinct from the reaction due to injection. The injections from this time were gradually
increased up to 5 minims, but the temperature never reached more than ror ${ }^{\circ} \mathrm{F}$.

About this time, although there was a certain diminution of the tumours, the patient had become morose and sullen, and was again complaining of headache and neuralgia. The treatment was suspended for about a fortnight, after which the fluid as obtained fron Dr. Coley was used.

April 27 th and 28th, mj was injected into one of the tumours, but there was no reaction. On April soth miv were injected, and the temperatur reached $99.8^{\circ} \mathrm{F}$. On April 3 oth $\mathrm{mvj}$ of fluid were injected; the temperature reached ror. $6^{\circ}$ two hour's after injection, remained up for an hour, but fell to normal six hours after injection. On May ist mvj produced a reaction to ro2. $5^{\circ} \mathrm{F}$; ; and on May 3 rd a reaction to ror. $5^{\circ} \mathrm{F}$. The growths all over were markedly less; the large nodulated mass on the left temple and behind the ear had almost disappeared. The injections were continued, mvj being given three times a week, the temperature of reaction
varying from ror

On June 7 th the patient was suffering from vomiting, getting very thin and complaining of shooting neuralgic pains on the right side of the head, occasional diplopia, great distaste of food, and very marked weakness. It was decided to stop the injections and to send him to the seaside before doing anything further. The tumours at this time were softer and smaller, and showed a marked tendency to wither more rapidly than heretofore. He ultimately went to Eastbourne, and I obtained the following report on June 25th:"His nights on the whole have not been good, as they have often been disturbed by attacks of more or less severe pain in the head and limbs. Vomits two or three times a day, generally, first thing in the morning, and frequently an hour or so aiter food." Dr. Talfourd Jones reported: "I have found the patient with the most extensive sarcomatous disease of the scalp, the whole of his head presenting an irregular, nodulated, pink or flesh-tinted fibro-plastic-looking growths, with considerable ichorous discharg enecessitating frequent cleansing with antiseptic lotions. He seems losing strength, complains of double vision, and sleeps badly

On July 3 rd I saw the patient at his own home, and found him then suffering intense neuralgic pain and somewhat delirious. The tumours of the scalp were smaller, some even had disappeared since I had seen him, but there was considerable slougling of some of the older masses at the back.

Death.-He died on July rgth, but, the doctor under whose care he was being away, his locum tenens did not inform me of the death, and I only heard of it some days after he was buried, and was thus prevented from having a post-mortem examination. Dr. Blatherwick informs me that for a fortnight before his death the vomiting quite ceased, and there was scarcely any pain. He was quite unconscious during the last week, but for a few days was very delirious and somewhat violent before ultimately sinking into a comatose state.

Pathological Report.-Prior to injection, the following report was obtained from the Clinical Research Association : "The growth consists of tained from the Clinical Research Association : "The growth consists of and stretching the epidermis so that the layer of papillæ is nearly comand stretching the epidermis so that the layer of papillæ is nearly completely effaced, and the epithelium is much thinned. The infiltration causes destruction of the connective tissue bundles, which become first broken up and distributed irregularly, and finally destroyed. In certain localities the connective tissue is arranged in fine parallel strands, having lines of the infiltrating cells between, and in this way simulating the arrangement of a lympho-sarcoma, but this occurs only in very limited localities, apparently in relation to the fibrous tissues surrounding the hair follicles. The growth is well supplied with blood vessels, and these and the type of any of the forms of angioma is not followed. In spite of the thinning of the epithelium, the arrangement of the normal layers of the epidermis can stin be made out. The stratum granulosum especially may be distinguished over the whole of the area examined. The thithelium of the hair follicles also seems to resist the infiltration, and the follicles, penetrating deeply into the substance of the tumour, retain their normal structure. In the portion submitted for examination no signs of
any of the forms of degeneration could be distinguished. The tumour, any of the forms of degeneration could be distinguished. The tumour

therefore, appears to be a round or oval-celled sarcoma of the corium." Bacteriological Report. - "Three organisms were isolated from the puru-
lent material. The first was a staphylococcus albus. The second the lent material. The first was a stapbylococcus albus. The second the
proteus vulgaris, and the third probably a form of proteus also, but which we cannot name, owing largely to "the meagre di scription of the se organisms in the textbooks."
In conclusion, the points of il terest seem to me to be :

1. The marked diminution in the tumours.

2. The fact of the powerlesi ness of the fluid to check the extension of the disease in this case.

3. Its exact value in cases of mycosis fungoides, and, if valuable, the exact stage at which it should be used in this disease; to my idea not in the first stage, and, indeed, not till the tumours have begun to show a tendency to remain permanent.

Lastly, it is somewhat unfortunate that the use of Coley's fluid has not been attended with the success in this country that it has in America. But this, I think, may be mainly due to the fact that it had not been tried sufficiently early, and that the doses used have been too :arge to begin with.

\section{NOTES ON A CASE OF SUICIDAL CUT-THROAT.}

\section{By HUGH GALT, M.B., C.M.Glasg., D.P.H.Camb.,} Professor of Forensic Medicine and Lecturer on Hygiene, St. Mungo's College, Glasgow; Pathologist to the Victoria Intirmary of Glasgow, etc.

THE case which forms the subject of the present note occurred on June 16th, 1898. A man, aged 39, cut his throat with a large bread knife about 6 A.M., and was found shortly afterwards lying on his face in a pool of blood. After preliminary medical attention he was taken to the Victoria Infirmary, but the loss of blood had evidently been very considerable, and he died shortly after 9 A.M., or about three hours after the act. I saw the body immediately after death, and made the following notes, looking at the case from a medico-legal point of view :

I. The extent of the wound was $4 \frac{1}{2}$ inches, $2 \frac{1}{2}$ being to the left and 2 to the right of the middle line.

2. The situation of the wound was, as is usual in suicidal cases, high up in the neck, being fully one-third of an inch above the level of the upper border of the thyroid cartilage.

3. The direction was, as one might a priori expect, from left to right. There was considerable "tailing" at both extremities, but particularly on the left side; in the latter situation there was a subsidiary notch running at an acute angle into the beginning of the incision proper, forming a $V$-shaped origin, as if the knife had been laid lightly and obliquely on the throat preliminary to the main incision. The line of incision was perfectly straight, showing no tendency to curvation at any point; moreover, it was perfectly transverse, the obliquity which is frequently present in such cases being conspicuous by its absence.

4. The depth of the wound was very great. In the middle line, and for about half an inch on either side of this, the knife had penetrated almost to the vertebral column, every intervening structure down to the posterior wall of the pharynx being severed, the latter itself being scored with the edge of the blade for about an inch transversely.

5. The structures involved included for about half an inch on each side of the middle line everything from the skin to the posterior wall of the pharynx, as already indicated. On the right side the wound terminated just short of the anterior border of the sterno-mastoid; on the left the sternomastoid showed a distinct notch in its anterior border. All the structures in front of the straight line joining the origin and termination of the wound were severed. It was clear that the head had been thrown well back when the wound was inflicted, as both internal jugulars and carotids escaped. The lingual artery on the left side was divided. A singular point was that a shaving had been taken off the lower border of the body of the hyoid bone. This last may have been due to the blade of the knife having been held with the edge pointing obliquely downwards and backwards, but there was no positive evidence on this point.

A superficial wound, about an inch and a half long, was present a little to the left of the middle line, and about half an inch beneath the level of the main incision. Death was evidently due to hæmorrhage. He had lost a large quantity of blood before he was found, and before the hæmorrhage was finally arrested a further proportion had escaped. Little blood was insufflated into the lungs, as there was no interference with respiration during the three hours of life. 
The fatal wound had evidently been made very rapidly, and with great force, as it is to be presumed that the edge of the knife used would hardly be so keen as that of a razor. The perfectly transverse nature of the wound was interesting, as indicating a sudden effort of very short duration; had the wound been an inch longer or more there is little doubt that one or both extremities would have been curved to some extent.

Post-mortem staining was quite distinct in the usual parts of the body posteriorly about 15 minutes after death. The body was allowed to lie on its back for 4 hours, and was then turned on its face. On the following morning, 24 hours after death, the post-mortem stains were entirely on the front of the body, and were well marked. In the right ventricle of the heart there was a large, well-formed, and adherent postmortem clot, with the usual distinct division into two layers, one being light yellow in colour, and containing no red corpuscles; the other, very dark, and containing all the red corpuscles in the clot; the yellow layer, however, was placed anteriorly, and in view of the position of the post-mortem stains this showed that the position of the body had been reversed some time after death. As the blood in the capillaries was still fluid, the post-mortem stains, when the body was again turned on its back, rapidly faded from the front and reappeared posteriorly.

With the view of informing myself as to the production of ecchymosis in a body after death, I used a spine chisel to inflict several very severe blows on the prominence of each shoulder, also over the left iliac crest, in the latter case employing sufficient force to produce a very palpable depression of the bone. This was done 20 minutes after death, and next morning the following appearances were noted: On the shoulders there was no mark which could be detected, while over the iliac crest there was an almost invisible lightgreenish coloration, corresponding to the depression of the bone, which would probably have escaped notice altogether had I not examined the part very carefully, with the knowledge of the blow which I had inflicted

With regard to motive, there seemed none, and the deed was apparently the result of temporary alcoholic insanity. The body was exceptionally well nourished, the layer of fat in the abdominal wall being an inch and a quarter thick; the internal organs were anæmic, the liver enlarged and fatty, the spleen shrunken, and the kidneys cirrhosed.

\section{A STUDY}

\section{of}

\section{TWO HUNDRED CONSECUTIVE OPERATIONS FOR THE RADICAL CURE OF HERNIA.} BY ARTHUR E. BARKER, F.R.C.S.,

Professor of the Principles and Practice of Surgery and Professor of Clinical Surgery at University College, and Surgeon to University College Hospital.

Is a paper which I had the honour to read before the Royal Medical and Chirurgical Society in April, I890; I analysed my first fifty cases of radical cure of hernia, and I venture to think that a brief study of a further 150 since consecutively operated on may have a certain value.

In the paper referred to three questions were taken as the basis of the inquiry upon which I hoped the 50 consecutive cases would furnish evidence:

1. Is the operation called for?

2. Is it safe $(a)$ as regards the patient's life; $(b)$ as regards the contents of the scrotum?

3. Does it secure against a return of the hernia?

In order to preserve a certain uniformity between the analysis of the succeeding 150 cases, these questions will be still taken as the text of the following inquiry, which in other respects as well will be made to follow the lines of the first commanication as nearly as possible.

The first question now hardly needs an answer, if the operative interference be limited to the young after infancy, and to those who are debarred from this or that calling by reason of the hernia. So far most surgeons are agreed; and in all the cases before me there was good reason for the measure. In many other cases the operation was refused, because there seemed to be very little special reason for its performance. In many cases, too, of strangulated hernia operated on during the same period, a radical cure was included in the procedure, but such are not recorded here, the inquiry being entirely confined to non-strangulated herniæ.

As to the risks of the operation for radical cure, if anything is learned from this series it is that the danger is small. Out of the 200 operations there were only three deaths. And when we consider that the procedure is a lengthy one, and that in many cases the conditions for which it was done were very complicated, and involved considerable risks even without operation, the mortality may be said to be low. And this point is further emphasised when we examine the cause of death in the three fatal cases.

One of these died of ether poisoning. The anæsthesia was begun with ether, which the patient took badly; then he was given chloroform, which was equally troublesome, and finally ether was again administered. Throughout the operation, which lassted 50 minutes, the patient showed considerable cyanosis and respiratory trouble, and just as I had finished, and was putting on the dressings, his breathing became more and more embarrassed, and finally ceased. Artificial respiration was unavailing, and death ensued. The man was 33 years of age, and was apparently healthy, and there was nothing unusual in the operation (Bassini's).

In both the other fatal cases it is a remarkable fact that I had to deal in each with a large irreducible inguinal hernia containing the sigmoid flexure of the colon, and in one of them (which had been irreducible for two years) the bladder was found in the sac with the sigmoid flexure, omentum, and large intestine.

In the first of these two, a man aged 6r, I was unable to reduce the bowel, and simply closed the wound at once, and the patient died some days later with symptoms of intestinal obstruction like several previous attacks of the same kind for which no cause could be found post mortem by the then Surgical Registrar, Mr. Raymond Johnson. There was no peritonitis.

In the second the operation was very long and very difficult. The patient, aged $5 \mathrm{I}$, was a large, gross-looking man, with an enormous left inguinal hernia, irreducible for the last two years. On cutting down on it the sac and other coverings were found greatly thickened, and there was much fluid in the sac, besides which the latter was very irregular and loculated. It contained the bladder, sigmoid flexure, large intestine, and omentum. With great difficulty the bulk of the contents was reduced. Then the main part of the sac was cut away, and the rest stitched up, after which it was pushed with the bladder and sigmoid flexure into the abdomen. The opening was closed by Bassini's method. Extensive suppuration followed, and septic peritonitis, from which the patient died on the fourth day. It is quite possible that here the septic matter may have reached the raw surface of the wound through the part of the sigmoid uncovered by peritoneum, and as the latter had to be handled pretty freely, I think this explanation tallies with the appearance seen post mortem. Not that the bowel had been perforated, but there is good reason to believe that intestine whose vitality is lowered in any way is traversed by the organisms living in its interior. And if this be true of bowel still covered by peritoneum, it ought to be equally, perhaps more, possible for the same thing to happen where the viscus was not so covered.

These three are the only instances in which death followed the operation among these 200 consecutive cases. But further than this, in no other case had the patient's condition appeared at any time critical. The recognised wound infections were unknown. Indeed, the vast majority healed absolutely by first intention under one dressing. On this point I have examined the series critically, and find that among them all there were 26 cases in which it may be said that there was definite discharge from the wound, varying from slight turbid oozing from a stitch hole or an unclosed angle to plain suppuration. But strictly speaking, in almost all these cases the discharge was very trifling, and in many of them the healing was the nearest thing possible to first intention. The remaining oases may all be said to have united primarily. There may have been here and there a spot of moisture round a stitch or where the epidermal edges were not absolutely in contact when the first dressing was applied, but this is not 